Forthcoming in Synthese

\title{
The Bifurcated Conception of Perceptual Knowledge: A New Solution to the Basis Problem for Epistemological Disjunctivism
}

\author{
Kegan J Shaw \\ University of Edinburgh
}

\begin{abstract}
Epistemological disjunctivism says that one can know that $p$ on the rational basis of one's seeing that $p$. The basis problem for disjunctivism says that that can't be since seeing that $p$ entails knowing that $p$ on account of simply being the way in which one knows that $p$. In defense of their view disjunctivists have rejected the idea that seeing that $p$ is just a way of knowing that $p$ (the $\mathrm{S}_{\mathrm{w}} \mathrm{K}$ thesis). That manoeuvre is familiar. In this paper I explore the prospects for rejecting instead the thought that if the $S_{w} K$ thesis is true then seeing that $p$ can't be one's rational basis for perceptual knowledge. I explore two strategies. The first situates disjunctivism within the context of a 'knowledge-first' approach that seeks to reverse the traditional understanding of the relationship between perceptual knowledge and justification (or rational support). But I argue that a more interesting strategy situates disjunctivism within a context that accepts a more nuanced understanding of perceptual beliefs. The proposal that I introduce reimagines disjunctivism in light of a bifurcated conception of perceptual knowledge that would see it cleaved along two dimensions. On the picture that results perceptual knowledge at the judgemental level is rationally supported by perceptual knowledge at the merely functional or 'animal' level. This supports a form of disjunctivism that I think is currently off the radar: one that's consistent both with the $S_{\mathrm{w}} \mathrm{K}$ thesis and a commitment to a traditional reductive account of perceptual knowledge.
\end{abstract}




\section{INTRODUCTION}

According to one version of epistemological disjunctivism, you can enjoy rational support for your perceptual beliefs on the basis of your seeing that $p$ to be the case. Since seeing that $p$ entails $p$, this provides you with a kind of factive rational support that you would not have unless $p$ were true. But doesn't seeing that $p$ also entail knowing that $p$ ? It can seem very natural to think so, on account of its just being a way of knowing that $p .{ }^{1}$ But if that is right then it seems that we can motivate this argument for thinking that disjunctivism is false:

\section{The Basis Argument against Disjunctivism}

1) Seeing that $p$ is just a way of knowing that $p .\left(S_{w} K \text { thesis }\right)^{2}$

2) If seeing that $p$ is just a way of knowing that $p$, then seeing that $p$ cannot serve as one's rational basis for knowing that $p$.

3) Therefore, seeing that $p$ cannot be one's rational basis for knowing that $p$.

This argument expresses what Duncan Pritchard calls 'the basis problem' for disjunctivism (Pritchard 2011, 2012, 2016). ${ }^{3}$ It's standard for disjunctivists to shy away from (2) and reject (1), or the $\mathrm{S}_{\mathrm{w}} \mathrm{K}$ thesis. Contrary to what we might have thought at first seeing that $p$ cannot simply be the way in which one knows that $p$, since seeing that $p$ doesn't entail believing that $p{ }^{4}$ That response is familiar. What remains unclear is what the prospects are for a version of disjunctivism that rejects (2) instead. There are good reasons for investigating those prospects.

\footnotetext{
${ }^{1}$ In what sense here is seeing that $p$ a way of knowing that $p$ ? Not in Cassam's sense (2009). For in that sense a way of knowing is simply a means of acquiring knowledge about something, and a means of knowing needn't entail knowledge (e.g. reading that $p$ doesn't entail knowing that $p$ ). Rather I think what we mean here is something like seeing that $p$ is identical to a piece of propositional knowledge, or realizes propositional knowledge. More on this below. See French (2014) for discussion.

${ }^{2}$ Cf. Ghijsen 2015

${ }^{3}$ Note that there are ways of formulating ED that aren't susceptible to the basis problem. These are formulations on which the rational support at issue isn't characterized in terms of your seeing that $p$ to be the case. See, e.g., French (2016) and Haddock (2011).

${ }^{4}$ See Pritchard (2012) (2016) and McDowell (2002b) for this line of response. They try to motivate a rejection of the WK thesis by describing cases that suggest that it's not obvious that this thesis is supported by our ordinary thought and talk about epistemic seeing. For example, suppose you see a zebra in clear view but suspend judgment on whether there's a zebra since you have a misleading defeater to the effect that it's a cleverly disguised mule. Pritchard and McDowell register the intuition that, after the fact, it'd be perfectly natural for you to describe yourself as having seen that there was a zebra, despite your not knowing that there was since you didn't believe that there was a zebra at the time.
} 
First Ghijsen (2015) argues that we have good reason to be suspicious of Pritchard's (2012) case against the $S_{w} K$ thesis. Whatever the merits of those arguments, we should like to have a sense of how else a disjunctivist might get around the basis problem if not by trying to motivate a rejection of the $S_{\mathrm{w}} \mathrm{K}$ thesis. Second, many find the idea that seeing that $p$ entails knowing that $p$ on account of simply being the way in which one knows that $p$ highly intuitive anyway, or at least very natural to assume (cf. Williamson 2000; Stroud 2009; Cassam 2007; Dretske 1969). ${ }^{5}$ If it were possible to defend disjunctivism against the basis problem without having to compromise on that idea, that would be a nice result for those interested in pursuing a disjunctivist approach to the rational support available for perceptual knowledge.

In this paper I explore two proposals for a defense of disjunctivism against the basis argument that leave the $S_{w} K$ thesis entirely intact. The first situates the disjunctivist's proposal within the context of a 'knowledge-first' approach to the relationship between perceptual knowledge and factive rational support for perceptual beliefs. ${ }^{6}$ That puts the disjunctivist in position to reject premise (2) on the basis of its wrongly assuming that we're advancing disjunctivism in service of a reductive account of perceptual knowledge. While this strategy is no doubt suitable for knowledge-firsters, it won't work for those like Pritchard who wish to advance disjunctivism in service of an account that reduces perceptual knowledge to a kind of rationally supported perceptual belief. To that end I explore a different proposal. If we situate ED within a context that accepts Ernest Sosa's (2015) distinction between 'intentional' and 'merely functional' modes of belief, we can reject (2) on the basis of its wrongly assuming a univocal conception of perceptual knowledge. What that means will become clearer in due course.

Ultimately I hope to articulate the beginnings of a form of epistemological disjunctivism that I think is currently off the radar: one that's consistent both with the $S_{\mathrm{w}} \mathrm{K}$ thesis and a commitment to offering an account of perceptual knowledge that reduces it to a kind of rationally supported perceptual belief.

\footnotetext{
${ }^{5}$ For further arguments for the entailment thesis, see French (2012) and Ranalli (2014). For a case against the entailment thesis see Turri (2010).

${ }^{6}$ By 'knowledge-first' I invoke the orientation in epistemology that most associate with the vision of 'Tim Williamson (2000).
} 


\section{A ‘KNOWLEDGE-FIRST’ SOLUTION TO THE BASIS PROBLEM}

\subsection{Disjunctivism and the Basis Problem}

I should begin by reviewing the core of epistemological disjunctivism and the basis problem that's meant to make trouble for it. As Pritchard (2012) (2016) defends epistemological disjunctivism, it is a view about the rational support available for perceptual knowledge. In particular, in paradigmatic cases you enjoy rational support for your perceptual knowledge comprised of your seeing that $p$ to be the case, where this is both factive and reflectively accessible to the subject. In this way seeing that $p$ can be the rational basis for perceptual knowledge.

Pritchard claims that disjunctivism enjoys the advantage of accommodating both 'externalist' and 'internalist' insights in epistemology with regard to perceptual knowledge. For insofar as your seeing that $p$ is reflectively accessible, we secure what internalists often complain is missing from externalist theories-viz., that when one knows something there ought to be good reasons that are the subject's reasons for adopting the relevant perceptual belief. But since seeing that $p$ is also factive, so that it entails that $p$, we also secure what externalists often complain is missing from internalist theories-viz., a sufficiently tight connection between one's epistemic support and the fact known. ${ }^{78}$ Among the view's problems is the basis problem: Seeing that $p$ can't serve as the rational basis for one's perceptual knowledge if seeing that $p$ just entails knowing that $p$ on account of simply being the way in which one knows that $p .{ }^{9}$

But why is that? How exactly does the $S_{w} K$ thesis make trouble for the idea that seeing that $p$ might serve as the rational basis for a bit of perceptual knowledge, so that premise (2) in the above argument can seem compelling?

\footnotetext{
${ }^{7}$ It's in this connection that Pritchard writes that epistemological disjunctivism represents the 'holy grail' of epistemology (2012, p.1).

${ }^{8}$ For criticism that ED doesn't capture the internalist's insight, see Boult (forthcoming), Madison (2014), and Goldberg (forthcoming). For criticism that there's no internalist insight for ED to capture, see Littlejohn (2015) (forthcoming). For criticism that ED doesn't capture the externalist's insight, see Kelp and Ghijsen (2016). ${ }^{9} \mathrm{ED}$ is susceptible to other problems, too: what Pritchard (2012) (2016) calls the access and distinguishability problems. There's also the problem of explaining why, given that one enjoys factive and reflectively accessible rational support for perceptual beliefs, it seems impermissible to assert that you know what you do in contexts where sceptical error possibilities have been raised. I don't speak to these other problems in this paper.
} 
Well imagine that the $S_{\mathrm{w}} \mathrm{K}$ thesis is true so that seeing that $p$ entails knowing that $p$ on account of being the way in which you know that $p$. In what sense then is seeing that $p$ the way in which you know that $p$ ? Well that's not merely to say that seeing that $p$ is the means by which you know that $p$. After all $x$ could be the means by which you know something even if $x$ does not entail that you know it. For example reading that $p$ could be the means by which you know that $p$, and yet you can read that $p$ without coming to know anything at all (cf. Cassam 2009). So if seeing that $p$ is the way in which you know that $p$ so that it entails that you know that $p$, seeing that $p$ isn't merely the means by which you know that $p$. Rather I think that what we want to say is that seeing that $p$ is identical to an item of propositional knowledge, or at least the specific "realization base" of an item of propositional knowledge (cf. French 2014 commenting on Williamson 2000). But then if that is the case then your putative rational basis for perceptual knowledge-your seeing that $p$-seems to 'presuppose' the very knowledge in question in a way that makes it look as though perceptual knowledge is epistemically supporting itself! (Ghijsen 2015). ${ }^{10}$ Many will strain to see how this is an even remotely illuminating account of everyday perceptual knowledge.

\subsection{The 'Knowledge-First' Strategy}

But perhaps this only seems like an unilluminating account because we are imagining that the disjunctivist is advancing their proposal in service of a traditional reductive account of perceptual knowledge. That is, an account that seeks to explicate the epistemic basis of perceptual knowledge in terms of factive rational support without referring to the perceptual knowledge at issue. If seeing that $p$ entails knowing that $p$ on account of just being the way in which you know that $p$ (as discussed above), then seeing that $p$ clearly seems ill-suited to serve as the epistemic basis of perceptual knowledge in an account like that. But what if we simply abandon that aspiration? What if instead we advance disjunctivism as an account of the rational support available for perceptual knowledge with no view towards reducing perceptual knowledge to a kind of rationally supported belief? In this way the disjunctivist might reject premise (2) by way of exposing that it rests on the false assumption that we are aiming for a

\footnotetext{
${ }^{10}$ Pritchard (2016, p. 127) writes that at best it would look like "one can appeal to seeing that $p$ to explain how one knows that $p$, but not to indicate one's epistemic basis for knowing that $p$." Ghijsen $(2015$, p. 1149) adds that "this would make the perceptual knowledge that $p$ literally self-supporting (...)". Thanks to a referee for helping me to be clarify exactly how SwK makes trouble for disjunctivism.
} 
traditional reductive account of the epistemic basis of perceptual knowledge. But how exactly does a disjunctivism like this work?

Alan Millar (2010) (2011b) (2016), for example, defends just such a view. For him, perceptual beliefs are rationally supported (or 'justified') although not known on the rational basis of one's seeing that $p$ to be the case. In fact, Millar is explicit that it's in part because one perceptually knows that $p$ that one enjoys this factive rational support. ${ }^{11}$ Millar writes that his account:

“(...) reverses the traditional philosophical order of explanation as between knowledge and justification in cases of perceptual knowledge (...). Possession of justification in these cases arises out of what we know about our environment and about our mode of perceptual access to it” (2011, p. 238).

For Millar we explicate the epistemic basis of perceptual knowledge not in terms of a rational basis to believe anything, but in terms of exercising certain perceptual-recognitional abilities (cf. Millar 2008, 2009, 2010). These are abilities to come to non-inferentially know of things in your environment that they are of some kind from the way they look. And so if on some occasion you know by seeing that something before you is a tomato, that's because you've exercised an ability to recognize tomatoes as tomatoes from the way they look-not because you've exploited some rational basis provided by your experience for thinking that it's a tomato.

But if seeing that it's a tomato is not the epistemic basis of your perceptual knowledge in this way, it might still function as the rational basis for your knowledge that it is a tomato. ${ }^{12}$ How is that? Well on Millar's view when you come to know that there is a tomato before you in response to a visual experience to this effect, you typically exercise not only an ability to tell of a tomato that it's a tomato, but also a higher-order ability to tell that you have exercised that lower-order ability — that is, an ability to tell of a tomato that it is a tomato that you see (cf. Millar 2011a, 2011 b, 2014, 2016) And so in response to the same visual experience, you

\footnotetext{
${ }^{11}$ Millar writes that "instead of explaining the knowledge as, so to speak, built up from justified belief, we treat the knowledge as what enables one to be justified in believing" (2010, p. 139).

${ }^{12}$ To clarify, by 'epistemic basis' I mean that in virtue of which one knows something. One's 'rational basis' may be that in virtue of which one knows something, in which case it will also be one's epistemic basis for that knowledge. But we should allow that one might enjoy a rational basis for their perceptual knowledge, despite one's not knowing on the basis of this rational support.
} 
typically come to recognize (and so know) not only that it's a tomato, but also that you see that it is a tomato.

This sets the stage for your seeing that there is a tomato to serve as the rational basis for your knowing that it is a tomato. After all, at least absent any other information, you would ordinarily think that there was a tomato before you only so long as you thought you were seeing that there was a tomato, and were to you abandon this later belief you would abandon the former as well. It's in virtue of sustaining your belief that there is a tomato in this way that your awareness of the fact that you see that there is a tomato serves as the rational basis for the bit of perceptual knowledge that, Millar is happy to allow, your seeing that there's a tomato entails. ${ }^{13}$

Thus if we follow Millar in situating disjunctivism within the context of a 'knowledgefirst' approach, it seems we are afforded an easy way out of the basis argument for disjunctivism. There is no need to reject the $S_{w} K$ thesis. Premise (2) is false. It only seems plausible insofar as it rests on the false assumption that we are advancing disjunctivism in service of an account that reduces perceptual knowledge to a kind of rationally supported perceptual belief. (For only then do we have some idea of what the complaint here could be-what in particular is wrong about perceptual knowledge rationally supporting itself. That is, we are prohibited from explicating the epistemic basis of perceptual knowledge while making reference to the very perceptual knowledge in question.) But once we abandon that aspiration within the context of the 'knowledge-first' approach it's no longer clear what the problem is supposed to be-why perceptually knowing that $p$ cannot furnish its own factive rational support.

That is all well and good for disjunctivists like Millar who are sympathetic to the knowledge-first approach. However, this sort of move is unavailable to disjunctivists like Pritchard who seek to advance a form of disjunctivism that's more in step with philosophical tradition. So long as we advance the view within the context of a 'reasons-first' approach that seeks a reductive account of what perceptual knowledge is like, we'll have to find some other way to dispel the impression that if seeing that $p$ is just the way in which you know that $p$ then disjunctivism is true only if perceptual knowledge is self-supporting in some vicious manner.

\footnotetext{
${ }^{13}$ Compare Millar when he writes: "Since it is constitutive of seeing that there are tomatoes in the basket that I believe that there are, it cannot be that I come to believe that there are in response to being apprised of the fact that I see that there are. Rather, I am in a position such that the reason I have to believe plays a role in sustaining the belief: were a question to arise as to whether there are tomatoes in the basket I would be liable to resist any suggestion that there are not in view of the fact that I see that there are, and were I to cease to believe that I see that there are then, all else equal, I'd cease to believe that there are" (2011 b, p. 332-33) (emphasis added).
} 
I think there is such a way. On a different approach, we situate disjunctivism not within the context of a 'knowledge-first' view, but within the context of a view of perceptual knowledge on the part of human beings that would see it cleaved along two dimensions. That is, into perceptual knowledge that's a species of what Ernest Sosa (2015) calls 'merely functional' belief, and perceptual knowledge that's a species of what he calls 'judgmental belief. I submit that by situating disjunctivism within the framework that Sosa provides, we can reject premise (2) on the basis of it's wrongly assuming something different-viz., a univocal conception of perceptual knowledge.

First I'll present the framework we find in Sosa. Then I'll show how a disjunctivist might apply the framework to the desired effect.

$\$ 2$

\section{THE BIFURCATED CONCEPTION OF PERCEPTUAL KNOWLEDGE}

In this section I'll draw on recent work from Ernest Sosa (2015) to describe what I'll call the bifurcated conception of perceptual knowledge on the part of mature human beings. I will then show how the disjunctivist might apply this conception for an interpretation of her view that is free of any conflict with the $S_{w} K$ thesis.

In Judgment and Agency (2015) Sosa writes that "we can distinguish between two sorts of 'belief', one implicit and merely functional, the other not merely functional, but intentional, perhaps even consciously intentional" (p. 80). He writes later that this distinction has "animal, action-guiding belief on one side, and the reflective judgments on the other" (p. 209). Sosa takes these to be different kinds of doxastic representation. How are they different from each other?

Sosa associates animal, action-guiding functional beliefs sometimes with "degrees of confidence", sometimes with "seemings", and sometimes with "credences". They're supposed to be "fully wired-in forms of representing" or "passive states that we cannot help entering" (p. 54) that are "acquired automatically" by way of "normal automatic processing" (p. 53).

By contrast, what Sosa calls "reflective, judgmental belief" (...) 
"(...) is a disposition to judge affirmatively in answer to a question, in the endeavor to answer correctly (...), reliably enough or even aptly. And this "judgment" that one is supposed to render is a distinctive conscious act or consciously sustained state” (p. 209).

Elsewhere Sosa adds that these judgmental beliefs are undergirded by a kind of "freely adopted evidential policy" with respect to a proposition, a policy residing in the will of the subject (p. 210). That suggests that these judgmental attitudes or commitments are constitutively sensitive to a rational basis of some sort—-to evidence or reasons for thinking them true. Let's illustrate this using a concrete case.

Imagine you perceive a tomato on the table in the 'good case' where epistemic conditions are objectively and subjectively good. Your perceptual and cognitive equipment are in fine order, there is nothing particularly abnormal about your environment, and you have not been given any relevant defeaters. If we take Sosa's view seriously that means that in response to what you see you form both judgmental and merely functional beliefs that it is a tomato before you. First, what exactly does it mean that you judgmentally believe this?

I take it that on Sosa's account this means that in that moment, in light of the reasons you take yourself to have for thinking the proposition true, you sustain a perceptual evidential policy such that were you to consciously consider whether just now a tomato is before you, you would affirm this proposition to yourself in an effort to thereby affirm knowledgably. ${ }^{14} \mathrm{By}$ sustaining that judgmental belief in that moment you reveal that you take your perceptual reasons to be good enough to warrant your affirming this proposition for the purpose of affirming knowledgeably, were you to take a moment and explicitly consider the matter. ${ }^{15}$ It might be helpful to contrast yourself with the Pyrrhonian sceptic, for example, who sustains a very different perceptual evidential policy. She is convinced that her perceptual reasons or evidence are never good enough for this kind of free judgmental affirmation-and so instead suspends on all such matters.

\footnotetext{
${ }^{14}$ In what follows I substitute 'knowledgeably' where Sosa would say 'aptly'. I think this is a safe substitution that shouldn't obscure my representation of Sosa's ideas. This is merely to avoid having to address the technicalities of Sosa's view of aptness with respect to belief, which would take us too far afield. Suffice it to say that, on Sosa's view, an apt belief is not simply true and competently formed, but true because competently formed. See also Sosa (2016).

${ }^{15}$ This isn't something I'm able to do, for instance, when merely guessing the answer to a question in a game show. Here I might affirm that, say, Columbus sailed in 1492 in effort to affirm truly (after all I want the prize, and you need true answers for that!). But I wouldn't be affirming to thereby affirm knowledgably, on Sosa's view. For him a truly judgmental belief isn't manifested in an intentional truth-aimed affirmation that amounts to a mere guess.
} 
By contrast, the way in which you merely functionally believe that there is a tomato before you requires no such ability to freely and intentionally affirm the truth of this proposition-it requires nothing at all so sophisticated. In sometimes referring to it as 'animal belief' Sosa suggests that this is a kind of representational attitude that we share with animals and small children. These seem to be what Daniel Dennett conceives of as "deep, behaviourdisposing states" that "one's behaviour is consonant with automatically" (p. 307,308). They are the sort of minimal doxastic attitude even the Pyrrhonian relies on to guide her behaviour when she reaches for the tomato into order to make a sandwich.

In Sosa then we find contrasted two kinds of doxastic representational state. Merely functional beliefs are representational states we find ourselves more or less saddled with as a result of the functioning of sub-personal processes. These are the states that, together with desire, are operative in motivating us to behave independently of any more sophisticated judgmental belief on our part. This later sort of belief, by contrast, itself has the look of an intentional action. It is a state of the subject that is rooted in her sustaining some evidential policy: One that requires her to affirm or vouch for the truth of a proposition, upon explicitly considering whether it's true, in light of what she takes to be good reasons for thinking the proposition true.

Doubtless there are many interesting questions and perhaps objections concerning how these different kinds of belief relate to one another in an individual. I'm afraid it would take us too far afield to entertain them just now. As I have been saying, my main concern is to discover whether one can employ Sosa's framework for articulating a form of disjunctivism that is both consistent with the entailment thesis and of piece with the traditional reductive approach. ${ }^{16}$ Now notice how this bifurcated conception of human belief naturally gives way to at least two species of perceptual knowledge. ${ }^{17}$ There is perceptual knowledge that is a species of merely functionally believing something. And there is perceptual knowledge that is a species of judgmentally believing something. Let's call perceptual knowledge of the former kind functional perceptual knowledge, and perceptual knowledge of the latter kind judgmental perceptual knowledge. Call the package the bifurcated conception of perceptual knowledge.

\footnotetext{
${ }^{16}$ For other examples of authors that seem to distinguish between at least two kinds of belief, see Daniel Dennett (1978), Gendler (2008), and Stevenson (2002), who actually distinguishes up to six different conceptions of belief. See also Neman (1870) who distinguishes between 'notional' assent and 'real' assent, and Frede (1998) who distinguishes 'having a view' from 'taking a position' on a matter.

${ }^{17}$ This shouldn't come as a surprise to anyone familiar with Sosa's work. He's long held to a distinction between so-called 'animal' and 'reflective' knowledge.
} 


\section{REVISTING THE BASIS PROBLEM}

With the bifurcated conception of perceptual knowledge now in tow, consider again the basis argument against disjunctivism:

\section{The Basis Argument Against Disjunctivism}

1) Seeing that $p$ is just a way of knowing that $p \cdot\left(\mathrm{S}_{\mathrm{w}} \mathrm{K}\right.$ thesis $)$

2) If seeing that $p$ is just a way of knowing that $p$, then seeing that $p$ cannot serve as one's rational basis for knowing that $p$.

3) Therefore, seeing that $p$ cannot be one's rational basis for knowing that $p$.

We noted above that premise (2) can seem compelling insofar as perceptual knowledge looks to be viciously self-supporting if the $S_{\mathrm{w}} \mathrm{K}$ thesis is true. But notice that if that doesn't wrongly assume that we are aiming for a reductive account of perceptual knowledge, then it assumes that the kind of perceptual knowledge that seeing that $p$ entails is the very kind that, at the same time, it is meant to rationally support. But now we are in position to expose that as a potentially false assumption. For if there is not one but two levels of perceptual knowledge of the same proposition in play, then there is room for a conception on which perceptual knowledge on one level rationally supports perceptual knowledge on another level.

For consider a picture on which it is specifically judgmental perceptual knowledge that is rationally supported by one's seeing that $p$. That seems like a natural fit anyway, given that we have already seen that judgmental belief seems to constitutively involve a kind of rational support that is exploited when one consciously affirms or endorses the truth of a proposition upon explicit consideration. On the current picture, then, in paradigmatic cases you enjoy rational support for your perceptual judgmental knowledge on the basis of your seeing that $p$ to be the case.

Now since we are exploring a strategy for defending disjunctivism against the basis problem that leaves the $S_{w} K$ thesis intact, we want to allow that seeing that $p$ is just the way in which one knows that $p$. But now there's a choice to make. In functioning to rationally support one's judgmental perceptual knowledge, does seeing that $p$ entail the very judgmental 
perceptual knowledge at issue? Or does it rather entail perceptual knowledge of a kind that is on the lower level-perceptual knowledge that is a species of merely functional belief? I cannot see anything that prevents the obvious choice here: that seeing that $p$ entails merely functional perceptual knowledge. On the picture that results, then, in paradigmatic cases we have something that entails merely functional perceptual knowledge rationally supporting judgmental perceptual knowledge. We have something that entails perceptual knowledge on one level rationally supporting perceptual knowledge on an entirely different level.

What is crucial about that is that nothing here looks to be viciously rationally supporting itself. Judgmental perceptual knowledge enjoys rational support on the basis of merely functional perceptual knowledge. And merely functional perceptual knowledge enjoys rational support on the basis of nothing at all, for all we need to say. In fact it seems perfectly natural that what you perceptually know at this merely functional 'animal' level you know not in virtue of any kind of reason that is your reason for believing what you do (but we are going to come back to this in the final section).

Moreover, note that none of this precludes advancing disjunctivism in service of a traditional reductive account of perceptual knowledge, one that explicates the epistemic basis of perceptual knowledge in terms of rational support without referring to the perceptual knowledge in question. After all, the target perceptual knowledge is a form of judgmental perceptual knowledge. And while its rational basis entails perceptual knowledge, this is perceptual knowledge at another order - that is, merely functional perceptual knowledge. Thus we have here the makings of a strategy for rejecting premise (2) of the basis argument that even disjunctivists like Pritchard could avail themselves of. For unlike Millar's strategy it does not require that we part so drastically with tradition on this score. On our proposal we safeguard the idea that perceptual knowledge (i.e. judgmental perceptual knowledge) can be reduced to a kind of rationally supported perceptual belief. ${ }^{18}$

\footnotetext{
${ }^{18}$ This is why our proposal is also preferable to a view that is like Millar's, with the exception that is offers a reductive externalist account of perceptual knowledge. On such a view we have only one kind of perceptual knowledge that receives a reductive externalist analysis. But such knowledge is also susceptible of further rational support courtesy of one's seeing that $p$ to be the case. Whatever the merits of a view like this, it is not able to sustain what I'm assuming is the relevant advantage secured by our proposal—viz., that it's consistent with the ambition of offering a certain reductive account of perceptual knowledge: one that reduces perceptual knowledge to a kind of rationally supported perceptual belief. I'm claiming that only a disjunctivism that integrates the bifurcated conception of perceptual knowledge is able to sustain that advantage without compromising on the SwK thesis. Thanks to a referee for the journal for encouraging me to make this clearer.
} 
This then paves the way for a rejection of premise (2), not on the grounds that it assumes that we are aiming for a traditional reductive account, but on the grounds that it assumes that we are operating with a univocal conception of perceptual knowledge. After all, that is false on a conception of disjunctivism that is advanced within the context of the bifurcated conception of perceptual knowledge. On that conception, judgmental perceptual knowledge is rationally supported by one's seeing that $p$, and seeing that $p$ entails knowledge that $p$, only knowledge that's a species not of judgmental but merely functional perceptual belief. It's no longer clear that there is anything to recommend premise (2) once we have made it clear that there are these two levels of perceptual knowledge in play. Once we have done that we remove the basis for the complaint that perceptual knowledge rationally supports itself in some vicious manner.

$\$ 4$

\section{RECONCILING OUR PROPOSAL WITH THE ORIGINAL MOTIVATIONS BEHIND EPISTEMOLOGICAL DISJUNCTIVISM}

Very well. Our proposal then has judgmental perceptual knowledge that $p$ enjoying factive rational support on the basis of something that is the way in which one merely functionally knows the proposition at issue. It remains to be seen though whether this rendition of epistemological disjunctivism can be reconciled with the original motivations for the view. In this final section I remove what might appear to be grounds for scepticism about that.

First, it is typical for epistemological disjunctivists to motivate their view by claiming that it captures both internalist and externalist insights with regard to perceptual knowledge. But isn't our proposal now in conflict with that ambition, since it has allowed merely functional perceptual knowledge into the picture-knowledge of a kind that appears to be thoroughly externalist in nature? I don't think so. For keep in mind that even if our proposal requires a kind of perceptual knowledge that is thoroughly externalist in this way, this is not the knowledge that it targets for a disjunctivist analysis. Rather the relevant target is judgmental perceptual knowledge. But then why shouldn't it it suffice for capturing the original motivation at issue that our theory of judgmental perceptual knowledge accommodates what internalists complain is missing from typical externalist accounts (i.e. that one should need to have good reasons for what they know), and what externalists complain is missing from typical internalist accounts (i.e. a sufficiently tight connection between one's epistemic support and the fact known)? And 
doesn't our account of judgmental perceptual knowledge accomplish just that? In other words it isn't clear why our proposal cannot be seen to accommodate both internalist and externalist motivations unless it can be seen to accommodate these with respect to both merely functional and judgmental perceptual knowledge. For this reason I don't see that our proposal is in any deep tension with the disjunctivist's original aim of providing an account of perceptual knowledge of the world that accommodates core internalist and externalist insights in epistemology. ${ }^{19}$

Second, some disjunctivists seem to motivate disjunctivism about perceptual knowledge on the grounds that knowledge in general requires a kind of 'internalist' factive rational support (cf. McDowell 1995, 2011; Littlejohn forthcoming). But clearly we cannot avail ourselves of that line of motivation once we have allowed for a kind of merely functional perceptual knowledge that needn't require 'internalist' rational support at all—much less factive rational support. I'll say just two things about this.

First, it isn't clear that our proposal need conflict with the thought that knowledge in general requires factive rational support. In the last section I only said that I think we are free to give merely functional perceptual knowledge a thoroughly externalist analysis, not that we are by any stretch compelled to. For all that needs to be said here, it may be that merely functional perceptual knowledge too requires factive rational support. Of course, we wouldn't want to say that this rational support is made available in the form of one's seeing that $p$ to be the case, for that would generate a new kind of basis problem, and most likely multiply notions of 'seeing that $p$ ' well beyond necessity. But you might think instead that one's rational support for merely functional perceptual knowledge is made available by the fact that $p$ itself (cf. Schnee 2016). That is, when you merely functionally know that it's a tomato before you, that it's a tomato is your rational basis for merely functionally believing this. In that case we would have a disjunctivism about merely functional perceptual knowledge embedded within a disjunctivism about judgmental perceptual knowledge. I don't claim to know of any arguments for thinking that that should be so. I only claim that that's one way of pursuing the details, a way that is

\footnotetext{
${ }^{19}$ Perhaps this is the thought behind the worry. Of course our proposal can't claim for itself that it's able to reconcile both internalist and externalist insights with respect to perceptual knowledge, so long as these are supposed to be insights into just any kind of perceptual knowledge whatsoever. Not if we allow merely functional perceptual knowledge to take a thoroughly externalist analysis (i.e. with no internalist' admixture). But then why think that? Why think that the externalist's and internalist's insights are real insights into just any kind of perceptual knowledge that there may be? Thanks to a referee for stimulating me to think about this some more.
} 
consistent with the thought that perceptual knowledge in general requires factive rational support.

But in any case, secondly, I don't think that you have to think that knowledge in general requires factive rational support in order to motivate disjunctivism about perceptual knowledge. For example, Duncan Pritchard (2012) (2016), who is as prominent a disjunctivist as any, considers disjunctivism to be amply motivated without the thought that knowledge in general requires factive rational support. ${ }^{20}$ After all, on his view, not only does disjunctivism represent a rapprochement between internalist and externalist insights regarding perceptual knowledge (as we reviewed above), but it also enables a unique 'undercutting' anti-sceptical solution to the underdetermination-based radical sceptical paradox (cf. 2016, p. 132-142). Moreover, it may be claimed that epistemological disjunctivism about some kind of perceptual knowledge is supported by our ordinary justificatory practises, wherein it would be very unnatural to defend a claim to perceptually know something by appealing to a kind of consideration you might have anyway, even if what you believed were false. ${ }^{21} \mathrm{I}$ submit that an epistemological disjunctivism advanced within the context of the bifurcated conception of perceptual knowledge is no less susceptible of these additional lines of motivation than, say, Pritchard's original account. Thus even if it turns out that our proposal conflicts with the thought that knowledge in general requires factive rational support, that would not be particularly devastating for the view. ${ }^{22}$

\section{CONCLUSION}

Perhaps we are used to thinking that so long as the $\mathrm{S}_{\mathrm{w}} \mathrm{K}$ thesis is true seeing that $p$ could not be the rational basis for perceptual knowledge, so that disjunctivists must therefore try to motivate a rejection of the $S_{\mathrm{w}} \mathrm{K}$ thesis. In this paper I set out to explore what the prospects are for a different route: one that avoids the basis problem without rejecting that thesis.

\footnotetext{
${ }^{20}$ Indeed he thinks that it's only in paradigmatic cases that one perceptually knows that $p$ by virtue of enjoying factive and reflectively accessible rational support in the form of one's seeing that $p$ to be the case. He explicitly denies that all knowledge, and even all perceptual knowledge, requires reflectively accessible and factive reasons (2015, forthcoming).

${ }^{21}$ Compare Pritchard (2016, p. 134-35): “(...) suppose I tell my manager over the phone that a colleague of mine is at work today (thereby representing myself as perceptually knowing this to be the case), and she expresses scepticism about this (...). In response I might naturally say that I know that she's at work today because I can see that she's at work (...). Indeed, wouldn't it be odd for me to respond in this case, given the situation as described, by offering nonfactive rational support, such as by saying that it seems to me as if she is at work (...)?”

${ }^{22}$ Thanks to a referee for the journal for encouraging me to think through the issues in this last section.
} 
This route scrutinizes premise (2) of the basis argument against disjunctivism: the thought that if the $S_{w} K$ is true then perceptual knowledge looks self-supporting in some problematic fashion. We saw that premise (2) can seem compelling only given one or another assumption: viz., either that the disjunctivist advances her proposal in service of a reductive account of the epistemic basis of perceptual knowledge, or else that the kind of perceptual knowledge seeing that $p$ entails is of the very kind that it at the same time rationally supports. Interestingly, either one or both of those assumptions might be false, depending upon how the disjunctivist chooses to situate her proposal. If she situates her proposal within the context of a 'knowledge-first' approach to the issues, the first assumption is false. If she situates her proposal in context of the bifurcated conception of perceptual knowledge, the second assumption is false.

A particularly interesting upshot of this discussion is that by employing the bifurcated conception of perceptual knowledge the disjunctivist can articulate her proposal in a way that is consistent both with the $\mathrm{S}_{\mathrm{w}} \mathrm{K}$ thesis and a commitment to providing a reductive account of everyday perceptual knowledge in terms of rationally supported perceptual belief. That seems to me to be an epistemological disjunctivism worth exploring further. ${ }^{23}$

23 Thanks to Duncan Pritchard, Martin Smith, Aidan McGlynn, Adam Carter, Giada Fratantonio, Lukas Schwengerer, Matt Jope, and Michel Croce for discussion of relevant themes. And thanks especially to two referees for Synthese for detailed comments on earlier drafts of this paper. 


\section{BIBLIOGRAPHY}

Boult, C. (forthcoming). 'An Explanatory Challenge for Epistemological Disjunctivism', Episteme.

Cassam, Q. (2007). 'Ways of Knowing', Proceedings of the Aristotelian Society, 107.3, 339-58.

Dennett, D. (1978). 'How to Change Your Mind', Brainstorms: Philosophical Essays on Mind and Psychology, 300-309, Bradford Books.

Dretske, F. (1969). Seeing and Knowing. Chicago: University of Chicago Press.

French, C. (2012). 'Does Propositional Seeing Entail Propositional Knowledge?', Theoria 78, $115-27$.

. (2014). 'Knowledge and Ways of Knowing', Proceedings of the Aristotelian Society $114,353-364$.

. (2016). 'The Formulation of Epistemological Disjunctivism', Philosophy and Phenomenological Research 92.1, 86-104.

Frede, M. (1998). 'The Sceptic's Two Kinds of Assent and the Question of the Possibility of Knowledge', The Original Sceptics: A Controversy, ed. M. Burnyeat and M. Frede, 127151, Hackett Publishing.

Gendler, T.S. (2008). "Alief and Belief", The Journal of Philosophy 105 (10): 634-63.

Ghijsen, H. (2015). 'The Basis Problem for Epistemological Disjunctivism Revisited”, Erkenntnis 80, 1147-1156.

Goldberg, S. (forthcoming). 'Comments on Pritchard's Epistemological Disjunctivism, Journal of Philosophical Research.

Haddock, A. (2011). 'The Disjunctive Conception of Perceiving', Philosophical Explorations 14 (1): $23-2$.

Kelp, C. and Ghijsen, H. (2016). 'Perceptual Justification: Factive Reasons and Fallible Virtues', Moral and Intellectual Virtues in Western and Chinese Philosophy, ed. M. Chienkuo, M. Slote, and E. Sosa, 164-83, London: Routledge.

Littlejohn, C. (2015). 'Knowledge and Awareness', Analysis 75 (4): 596-603. 
. (forthcoming). 'Pritchard's Reasons', Journal of Philosophical Research.

Madison, B. (2014). 'Epistemological Disjunctivism and the New Evil Demon', Acta Analytica $29(1), 61-70$.

McDowell, J. (1982). 'Criteria, Defeasibility, and Knowledge', Proceedings of the British Academy 68, 173-192.

. (1994). 'Knowledge by Hearsay', Knowing from Words: Western and Indian

Philosophical Analyses of Understanding and Testimony, ed. B.K. Matilal and A.

Chakrabarti, 195-224, Dordrecht: Kluwer Academic Publishers.

. (1995). 'Knowledge and the Internal', Philosophy and Phenomenological Research $55,877-893$.

. (2002a). 'Knowledge and the Internal Revisited, Philosophy and Phenomenological Research 64, 97-105.

. (2002 b). 'Responses', Reading McDowell: on Mind and World, ed. N.H. Smith, 269-305, London: Routledge. Press.

. (2011). Perception as a Capacity for Knowledge, Milwaukee: Marquette University

Millar, A. (2007). 'What the Disjunctivist is Right About', Philosophy and Phenomenological Research 74.1, 176-199.

. (2008). 'Disjunctivism and Scepticism', The Oxford Handbook of Scepticism, ed. J. Greco, 581-601, Oxford: Oxford University Press.

. (2009). 'What is it that Cognitive Abilities are Abilities to Do?' Acta Analytica 24,

233-236.

, Pritchard, D., Haddock, A. (2010) The Nature and Value of Knowledge: Three Investigations, Oxford: Oxford University Press.

. (2011a). 'Knowledge and Reasons for Belief', Reasons for Belief, ed. A. Reisner and A. Steglich-Peterson, 223-43, Cambridge: Cambridge University Press.

. (2011b). 'How Visual Perception Yields Reasons for Belief', Philosophical Issues 21, $332-351$.

. (2014). 'Reasons for Belief, Perception, and Reflective Knowledge', Proceedings of the Aristotelian Society 88, 1-19.

. (2016). 'Perceptual Knowledge and Well-Founded Belief', Episteme 31, 43-59.

Newman, J.H. (1870). An Essay in Aid of A Grammar of Assent, London: Burns, Oats, \& Co. 
Pritchard, D. H. (2011). 'Epistemological Disjunctivism and the Basis Problem', Philosophical Perspectives 21 (1), 434-455. . (2012). Epistemological Disjunctivism, Oxford: Oxford University Press. 637.

(2015). 'Epistemological Disjunctivism: Responses to My Critics', Analysis 75.4, 627. (2016). Epistemic Angst: Radical Scepticism and the Groundlessness of our Believing. New Jersey: Princeton University Press.

. (forthcoming). 'Epistemological Disjunctivism: Responses to My Critics', Journal of Philosophical Research.

Ranalli, C. (2014). 'Luck, Propositional Perception, and the Entailment Thesis', Synthese 191, 1223-1247.

Schnee, I. (2016). 'Basic Factive Perceptual Reasons', Philosophical Studies, 173.4: 1103-1118.

Shaw, K. (2015). 'Religious Epistemological Disjunctivism', International Journal for Philosophy of Religion 79 (3), 261-279.

. (forthcoming). 'A Better Disjunctivism Response to the 'New Evil Genius' Challenge, Grazer Philosophische Studien.

Stroud, B. (2009). 'Scepticism and the Senses', European Journal of Philosophy, 17.4, 559-570.

Smithies, D. (2013). 'Review of Duncan Pritchard, Epistemological Disjunctivism', Notre Dame Philosophical Reviews.

Sosa, E. (2015). Judgment and Agency, Oxford University Press. . (2016). 'Epistemic Competence and Judgment, Performance Epistemology: Foundations and Applications, ed. M. Angel and F. Vargas, 20-29, Oxford: Oxford University Press.

Stevenson, L. (2002). 'Six Levels of Mentality', Philosophical Explorations 5.2, 105-1124.

Turri, J. (2010). “Does Perceiving Entail Knowing?” Theoria 76, 197-206.

Williamson, T. (2000). Knowledge and its Limits, Oxford: Oxford University Press. 